\title{
0 Uso de Compósitos Estruturais na Indústria Aeroespacial
}

Após décadas de uso restrito em alguns setores da indústria, como na área de mísseis, foguetes e aeronaves de geometrias complexas, os compósitos poliméricos estruturais, também denominados avançados, têm ampliado a sua utilização em diferentes setores da indústria moderna, com um crescimento de uso de $5 \%$ ao ano. Atualmente, a utilização de estruturas de alto desempenho e com baixo peso tem sido feita nas indústrias automotiva, esportiva, de construção civil, entre outras.

A partir da década de 60 , os materiais compósitos de alto desempenho foram introduzidos de maneira definitiva na indústria aeroespacial. O desenvolvimento de fibras de carbono, boro, quartzo ofereceram ao projetista a oportunidade de flexibilizar os projetos estruturais, atendendo as necessidades de desempenho em vôo de aeronaves e veículos de reentrada. Em paralelo, os compósitos carbono/ carbono (compósitos de Carbono Reforçados com Fibras de Carbono-CRFC) e tecidos de fibras de quartzo foram desenvolvidos e submetidos a severas condições térmicas e de erosão, em cones dianteiros de foguetes, em partes externas de veículos submetidos à reentrada na atmosfera terrestre e em aviões supersônicos. Os avanços dos compósitos criaram novas oportunidades para estruturas de alto desempenho e com baixo peso, favorecendo o desenvolvimento de sistemas estratégicos, como na área de mísseis, foguetes e aeronaves de geometrias complexas.

Durante o conflito no sudeste da Ásia, no Vietnã, em ambiente de floresta, novos desafios surgiram na área de materiais. Como consequiência, novos plásticos foram desenvolvidos para atender a indústria de eletroeletrônicos, que necessitava de maior resistência a climas úmidos. Revestimentos de aeronaves também foram obtidos especificamente para minimizar os efeitos de corrosão, erosão e minimizar sinais de infravermelho. Outros plásticos foram pesquisados visando a confecção de pára-quedas e a construção de artefatos mais resistentes a fluidos hidráulicos.

Com o advento da corrida espacial novos desenvolvimentos foram feitos na área de compósitos carbono/carbono, com maior resistência à oxidação, garantindo o seu uso em gargantas de tubeiras de foguetes impulsionados à base de propelente sólido e cones de exaustão de aeronaves.

No conflito com o Iraque, mais uma vez, a indústria aeronáutica surpreendeu o setor tecnológico com o lançamento da aeronave F-117, construída em compósitos de fibras de carbono com matrizes epóxi e bismaleimida, apresentando, ainda, a característica de baixa detecção por radares. A geometria desse avião, associada ao uso de materiais compósitos e revestimentos específicos, que favorecem a absorção da radiação eletromagnética na faixa de microondas, ainda hoje são marcos impressivos de inovação das engenharias aeronáutica e de materiais.

Após décadas de uso restrito em alguns setores da indústria, devido ao seu custo de obtenção, os compósitos poliméricos estruturais, também denominados avançados, têm ampliado a sua utilização em diferentes setores da indústria moderna, com um crescimento de uso de $5 \%$ ao ano. Atualmente, a utilização de pré-impregnados (tecido ou cabo de reforço contínuo, impregnado com resina no estágio B) na manufatura de artefatos em compósitos estruturais está distribuída, ao nível mundial, nos seguintes ramos da indústria: aeronáutico comercial $60 \%$, defesa e espaço $20 \%$, recreativo $10 \%$ e indústrias em geral $10 \%$. Com relação ao tipos de reforços, os setores aeronáutico/defesa/espaço utilizam $60 \%$ de pré-impregnados unidirecionais ( $t a$ pes) e $40 \%$ de tecidos bidirecionais, o setor recreativo $80 \%$ de reforços unidirecionais e $20 \%$ de tecidos bidirecionais e os demais setores $10 \%$ de tecidos e reforços unidirecionais e $90 \%$ de reforços tipo nãotecidos (nonwoven reinforcements). Com relação às matrizes poliméricas utilizadas na impregnação dos reforços, $40 \%$ são do tipo epóxi, $20 \%$ relativas a sistemas para uso em 
mais altas temperaturas, em relação à epóxi, tipos bismaleimidas e alguns termoplásticos e $40 \%$ demais tipos de resinas.

Mais recentemente, mesmo no setor aeroespacial, a obtenção de componentes em compósitos estruturais tem procurado correlacionar as propriedades dos materiais, o desempenho estrutural do componente e os diferentes processos de manufatura com a redução de custo. Processos que favoreçam maior produtividade a menores custos $\mathrm{e}$ com qualidade compatível à utilização do produto estão sendo investigados. Com isto, os compósitos avançados têm ampliado as suas aplicações em outras áreas da engenharia, ao nível mundial. Exemplos de alguns desses processos são a moldagem por transferência de resina assistida a vácuo (Vaccum-Assisted Resina Transfer Molding - VARTM) e a moldagem por transferência de resina (Resin Transfer Molding - RTM), bem como, numerosas modificações de processos básicos têm sido realizadas recentemente. Essas inovações têm propiciado uma maior utilização desses compósitos nos setores de transporte, artigos esportivos, médicos e, mais recentemente, na área da engenharia de construção.

Neste contexto, o Brasil tem ampliado a sua experiência de inovação na aplicação dos compósitos estruturais, principalmente, no setor aeronáutico, utilizando este tipo de material em componentes externos e internos de aviões (cerca de $20 \%$ da área de uma aeronave) e helicópteros e, em menor escala, na estrutura de foguetes. Em apoio, principalmente, aos trabalhos em andamento no Instituto de Aeronáutica e Espaço do Centro Técni- co Aeroespacial e à indústria aeronáutica nacional e suas ramificações, trabalhos de pesquisa e desenvolvimento têm sido realizados na Divisão de Materiais, enfocando o uso de diferentes matrizes poliméricas, otimização de processos e melhoria de propriedades mecânicas, principalmente pelo estudo de interfaces fibra/matriz e tratamento superficial de reforços.

\section{Setor Aeroespacial}

Historicamente, estruturas aeronáuticas em compósitos têm sido fabricadas utilizando-se fibras longas, com comprimento igual à dimensão do componente que está sendo manufaturado. Dessa maneira, ocorre a máxima transferência das propriedades mecânicas da fibra para o compósito (sob determinadas condições de carregamento das fibras). No entanto, a fabricação de estruturas complexas, utilizando fibras contínuas, exige uma significativa quantidade de trabalho manual ou equipamentos complexos e caros de corte do reforço e laminação dos pré-impregnados. Em função disso, trabalhos recentes têm combinado o uso de préformas de fibras secas e picadas e processos de transferência de resina, visando ampliar o uso de compósitos poliméricos em componentes de estrutura secundária (com menor exigência estrutural). O resultado desses trabalhos mostra vantagens de custo e processabilidade e na relação peso/ resistência, em comparação ao componente metálico substituído.

A utilização de compósitos poliméricos avançados em partes estruturais de aeronaves cresce a cada ano, devido às excelentes pro- priedades mecânicas que este material confere ao componente que está sendo projetado e por permitir flexibilidade no projeto de peças complexas e com propriedades locais específicas. Hoje, a empresa americana Hexcel Corporation, fornecedora de pré-impregnados (tecido ou cabo de reforço contínuo, impregnado com resina no estágio B) homologados internacionalmente para serem utilizados na manufatura de componentes aeronáuticos estruturais, já movimenta mais de 1 bilhão de dólares, fornecendo para empresas como a Boeing, Bombardier e EMBRAER.

O crescente uso de polímeros reforçados com fibras de carbono no setor aeronáutico deve-se, principalmente, ao constante desafio que esta indústria possui na obtenção de componentes que exibam os maiores valores de resistência mecânica e de rigidez específicas entre os materiais disponíveis. A substituição do alumínio por compósitos poliméricos estruturais, por exemplo, permite uma redução de peso de 20 a $30 \%$, além de $25 \%$ na redução do custo final de obtenção das peças.

Hoje, os compósitos de fibras contínuas com matriz termorrígida estão sendo utilizados na obtenção de componentes internos, externos, nervuras de asas em aeronaves da Boeing, portas de trens de aterrissagem, radome do Hércules, flapes, partes estruturais do F-16, bordas de ataque, entre outras.

O processo mais utilizado na fabricação dos compósitos poliméricos termorrígidos tem sido a cura em autoclave de peças laminadas manualmente. Com o objetivo de otimizar a produção desses compósitos com qualidade para aplicação aeroespacial, estudos têm 
sido realizados sobre o efeito de delaminação em bordas livre e moldada de compósitos com diferentes arranjos de fibras e sobre a influência da porosidade nas propriedades mecânicas finais do material obtido. Entretanto, existem muitos outros processos atualmente em uso, podendo-se citar a pultrusão, bobinagem, a trançagem com ângulos e densidades de fibras pré-determinados (braiding), RTM, etc.

Apesar da matriz epóxi ser ainda muito utilizada no processamento de compósitos, uma nova geração de resina termorrígida modificada com termoplásticos, as bismaleimidas (BMI), está sendo utilizada nas mais importantes e complexas aplicações de alto desempenho no setor aeronáutico, podendo-se citar na aeronaves F-22, F-117 e B-2, do programa militar americano. Na área civil, compósitos com este tipo de matriz vêm sendo utilizados na indústria de carros de fórmula-1. Os compósitos com bismaleimida apresentam a combinação única de alta temperatura de serviço, excelentes propriedade mecânicas até cerca de $180^{\circ} \mathrm{C}$ em condições úmidas, exibindo tolerância a danos superior às melhores resinas epóxi. Certas BMI são capazes de serem utilizadas na faixa de temperatura de $232-288^{\circ} \mathrm{C}$, apresentando comportamento semelhante à poliimida PMR-15. As BMI, também, permitem o uso do processo RTM.

A aeronave supersônica F-22, que atinge velocidades de 1,5 Mach, utiliza em sua estrutura $24 \%$ de material compósito polimérico, $39 \%$ de titânio, $16 \%$ de alumínio, $6 \%$ de aço e $15 \%$ de outros materiais. Sendo que, $50 \%$ do peso em compósito é constituído da matriz de resina
BMI. A aeronave F-22, apesar de suas velocidades de vôo, não utiliza em suas superfícies externas material retardante de chama, devido às características de resistência térmica e química da BMI.

A Figura 1 apresenta a aeronave Tucano produzida pela EMBRAER, mostrando os componentes fabricados em compósitos termorrígidos, utilizando como reforço fibras de carbono, kevlar e vidro.

O uso de compósitos termoplásticos reforçados com fibras contínuas também tem sido ampliado no setor aeroespacial, devido, principalmente, à redução drástica da fadiga, maiores valores de resistências ao impacto e ao fogo, baixa absorção de umidade, temperatura de serviço mais elevada e grande versatilidade na produção em série, exibindo propriedades mecânicas iguais ou superiores às apresentadas pelos compósitos termorrígidos. No setor aeronáutico, o uso de compósitos termoplásticos é promissor na construção de fuselagens, permitindo com isto uma redução de peso em torno de $25 \%$, em relação às estruturas metálicas hoje utilizadas. Hoje, dois processos tecnológicos estão sendo estudados, de modo a ampliar o uso deste tipo de compósitos sem, no entanto, onerar em demasia os custos com a aquisição de novas ferramentas de moldagem. O primeiro processo, conhecido como termoformagem de laminas, consiste em laminar os pré-impregnados e pré-consolidar por prensagem a quente. Estes laminados são, então, cortados e moldados na obtenção da peça. $\mathrm{O}$ segundo processo é conhecido como consolidação in-situ, o qual utiliza a laminação contínua e a consolidação direta da peça. Hoje, estes compósitos estão sendo utilizados na obtenção de componentes externos, como portas de aeronaves da Boeing e da Fokker.

Vários polímeros de última geração estão sendo utilizados na obtenção destes compósitos destacando-se: poliamidas, poliimidas, PEEK [poli(éter-éter-cetona)], PEI [poli(éter-imida)], PPS [poli(sulfeto de fenileno)], PSU (polisulfona), entre outros, atendendo a requisitos de resistência mecânica na faixa de -60 a $200^{\circ} \mathrm{C}$, utilizando processos como a moldagem por compressão a quente, a pultrusão reativa, a injeção e o RTM.

No setor aeroespacial tem-se, ainda, os compósitos carbono/carbono constituídos por uma matriz de carbono, proveniente de precursores à base de resinas ou piches. Esta classe de compósito termoestrutural procura aliar as propriedades de alto desempenho das fibras de carbono com as características singulares do carbono. Os materiais carbonosos, em suas diferentes formas estruturais, apresentam alta resistência mecânica em temperaturas de até $2800^{\circ} \mathrm{C}$, na ausência de oxigênio, boa resistência à corrosão, baixa expansão térmica, inércia química e resistência a variações súbitas de temperatura. Estas propriedades tornam este material atrativo para aplicações a elevadas temperaturas $\left(800-2500^{\circ} \mathrm{C}\right)$ em atmosfera inerte e condições ablativas.

Embora existam todas estas vantagens, a aplicação do carbono tem sido limitada pela baixa deformação na ruptura, alta sensibilidade a imperfeições, anisotropia, variabilidade nas propriedades, dificuldades no processo de obtenção de componentes de grandes dimensões e formatos complexos. Além disso, 


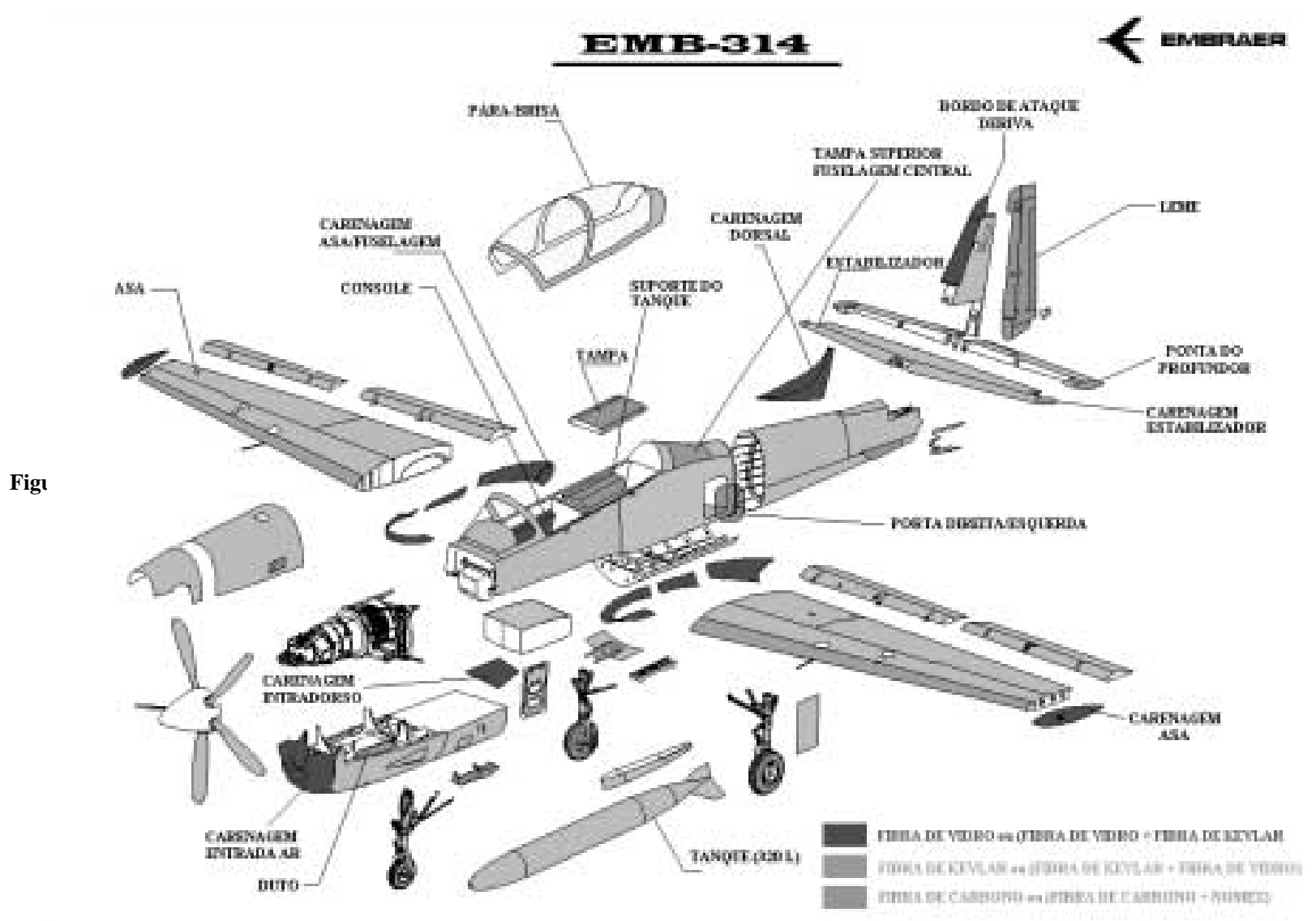

devido ao seu elevado custo, comparado com outros materiais, a sua aplicação está restrita às áreas aeroespacial, nuclear, biomédica e algumas aplicações especiais.

Outro fator limitante da utilização do CRFC é a sua susceptibilidade à oxidação a temperaturas de aproximadamente $500^{\circ} \mathrm{C}$, sob ar. Porém, isto pode ser minimizado fazendo-se o recobrimento de sua superfície com antioxidantes adequados. Quando a temperatura de aplicação está na faixa entre $500-600^{\circ} \mathrm{C}$, a inibição pode ser obtida utilizando-se compostos inorgânicos como óxido de boro e fosfatos. Quando a temperatura de utilização for maior que $600{ }^{\circ} \mathrm{C}$, costuma-se recobrir o CRFC com carbeto de silício, carbeto de titânio, entre outros.
Apesar do CRFC ser susceptível à oxidação a temperaturas superiores a $500{ }^{\circ} \mathrm{C}$, este fator torna-se menos relevante quando a aplicação do compósito for por um curto período de duração, como nos casos de gargantas de tubeiras de foguetes à base de propelente sólido ou componentes com a função de proteção térmica, como em mísseis e veículos de reentrada. Ainda no campo aeroespacial, os CRFC estão sendo utilizados em bordas de ataques de aeronaves supersônicas e do ônibus espacial (Space Shuttle) da NASA, componentes estes que chegam atingir temperaturas de até $1500{ }^{\circ} \mathrm{C}$, devido ao atrito com a atmosfera e, em sistemas de freios de aeronaves supersônicas militares e civis (como o Concorde), devido à sua baixa taxa de desgaste com a temperatura, aos bons coeficientes de atrito e de calor específico, que proporcionam um atrito brando durante o período de frenagem. O potencial de frenagem do compósito carbono/carbono é cerca de quatro a cinco vezes superior aos sistemas convencionais (metálicos) aumentando, assim, a segurança da aeronave. Este sistema oferece, ainda, uma economia de peso, comparado com os convencionais.

O processamento do CRFC tem como fase intermediária a obtenção de compósitos carbono/ fenólica. Estes compósitos poliméricos reforçados com fibras de carbono, além de serem materiais precursores dos CRFC, têm encontrado aplicações termo-estruturais como proteção térmica de foguetes. Na tecnologia de propulsão de 
foguetes que usam combustíveis sólidos, os compósitos carbono/ fenólica têm papel fundamental como o suporte da garganta de tubeira em CRFC, protetor térmico na região de saída dos gases de queima do propelente e nas re-

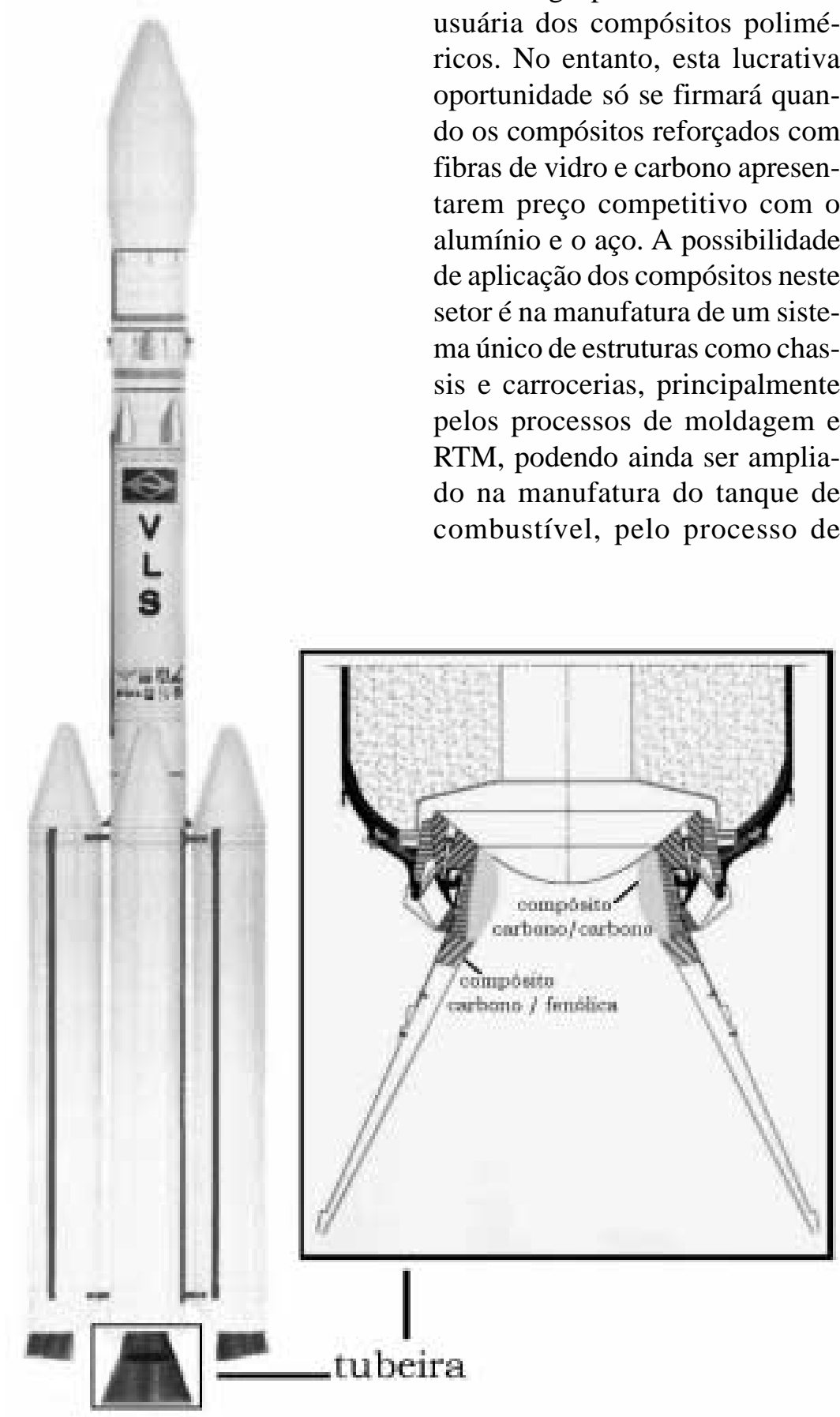

Figura 2. Esquema de uma garganta de foguete produzida pelo CTA mostrando o uso de compósitos carbono/carbono e carbono/fenólica.

giões anterior e posterior à garganta (Figura 2).

\section{Transporte}

A tendência mundial mostra que a indústria automotiva a médio e longo prazos será a maior usuária dos compósitos poliméricos. No entanto, esta lucrativa oportunidade só se firmará quando os compósitos reforçados com fibras de vidro e carbono apresentarem preço competitivo com o alumínio e o aço. A possibilidade de aplicação dos compósitos neste setor é na manufatura de um sistema único de estruturas como chassis e carrocerias, principalmente pelos processos de moldagem e RTM, podendo ainda ser ampliado na manufatura do tanque de combustível, pelo processo de bobinagem, entre outras. Hoje, esta indústria já faz uso de polímeros e de compósitos com fibras picadas na fabricação de componentes sem exigência estrutural primária.

Com relação aos compósitos carbono/carbono, hoje estes materiais já são utilizados como discos de freios em carros de formula- $1 \mathrm{e}$ trens de alta velocidade, em substituição ao asbestos.

\section{Indústria da Construção Civil}

Durante muito tempo os compósitos poliméricos têm sido utilizados basicamente para reparos e adequações de pontes e edificações danificadas. No entanto, a deterioração da parte pavimentada das pontes (leito da ponte) é considerado um sério problema de infraestrutura. Tal desafio tem levado à investigação de materiais não-convencionais para solucionar esses problemas. Avanços na manufatura de compósitos poliméricos reforçados com fibras, somado aos valores de resistência e rigidez desses materiais nas condições de uso, simulados em laboratório, levaram à produção, nos Estados Unidos da América no estado da Virgínia, de módulos de leitos de pontes para reparos temporários ou permanentes. Inicialmente, o custo desses leitos em material compósito é cerca de $60 \%$ maior que o correspondente à produção de leitos em concreto. No entanto, a busca por uma produção em escala industrial e o menor peso desses leitos, facilitando o seu transporte e a sua colocação final, têm motivado a continuidade dos trabalhos de substituição de materiais convencionais. Uma outra área da indústria da construção civil que tem dedicado atenção especial aos compósitos poliméricos 
estruturais, na tentativa de minimizar o peso das estruturas e diminuir os riscos de desabamentos, mantendo as mesmas características mecânicas dos materiais convencionais, é a construção de edificações em áreas sujeitas a abalos sísmicos.

A prática da trançagem de fibras (braiding) foi, por muito tempo, utilizada para a obtenção de estruturas simples, de uso decorativo ou como cordas. Atualmente este processo vem sendo utilizado na manufatura de componentes aeroespaciais e mais recentemente na produção de hastes, estacas e tubos de menor peso aplicados no setor da construção civil, como componente com exigências estruturais. O uso de fibras estruturais como carbono, vidro, aramida tem viabilizado a obtenção de pré-formas trançadas, com a combinação de fibras ou não, cilíndricas ou planas, impregnadas com termorrígidos ou termoplásticos. Estas estruturas trançadas, dependendo dos tipos de fibra e matriz polimérica utilizados têm apresentado, em geral, preço competitivo, com interessantes valores de resistência e rigidez, resistência à corrosão e menor peso.

\section{Células Combustível}

Os compósitos carbono/carbono além de suas aplicações no setor aeroespacial têm encontrado aplicações em células combustível como eletrodos e outros componentes estruturais, devido à sua excelente resistência à corrosão e boas propriedades térmicas e elétricas. A maioria das células combustível modernas é baseada no uso de eletrólitos à base de ácido fosfórico como eletrólito, operando a $204^{\circ} \mathrm{C}$ e gerando de $200 \mathrm{~kW}$ a $11 \mathrm{MW} \mathrm{d}$ energia elétrica. Estas células individuais são ligadas em série formando módulos. A combinação de muitos desses módulos são utilizados para formar um gerador de energia. Protótipos dessas células com compósitos CRFC têm mostrado bons resultados, porém a viabilização de seu uso depende, ainda, da redução do custo e do tempo de preparação do compósito.

A aplicação dos compósitos CRFC em reatores de energia por fusão e fissão também é promissora por apresentar como características: baixo número atômico, baixa seção de choque com neutrons, alta estabilidade térmica, não se funde, excelente resistência ao choque térmico, tolerância a danos por neutrons, baixo coeficiente de expansão térmico, alta resistência mecânica, baixo módulo de Young, resistência à erosão por jateamento de plasmas e baixa liberação de gases.

O CRFC também pode ser utilizado na confecção de cápsulas de proteção de isótopos utilizados em missões espaciais para gerar calor e eletricidade.

\section{Outras Aplicações}

$\mathrm{Na}$ área médica os materiais compósitos poliméricos têm encontrado aplicação na confecção de próteses ortopédicas externas e o compósito carbono/carbono em próteses ortopédicas internas.

O compósitos poliméricos reforçados com fibras de carbono têm sido utilizados, também, em sistemas de antenas, devido às suas boas propriedades de reflexão de rádiofrequiência, alta estabilidade dimensional e boa condutividade elétrica. Isto inclui antenas parabólicas, subrefletores e estruturas traseiras de emissores de rádio-freqüência. Já os compósitos com fibras de vidro e kevlar vêm sendo utilizados como material transparente à radiação eletromagnética na faixa de microondas, sendo aplicados na manufatura de radomes de aeronaves (nariz do avião), tendo como função proteger o radar de busca e imageamento, sem interferir na radiação emitida ou recebida pelo radar.

Os compósitos poliméricos obtidos pelo processo de trançagem e/ou pultrusão têm sido utilizados na manufatura de artigos esportivos como tacos de basebol, de hóquei, varas de pescar, esqui para uso em esportes aquáticos e em neve, estruturas de bicicletas, entre muitos outros artigos utilizados nesta área.

Uma outra área que vem se beneficiando das propriedades de resistência mecânica e menor peso dos compósitos estruturais é a de construção de plataformas offshore e de equipamentos para a extração de petróleo em alto mar. O uso de compósitos obtidos pelo processo de bobinagem tem oferecido muitas vantagens nesta área, permitindo o projeto de tubos com as características desejadas à aplicação, em função da escolha correta da fibra, matriz e da orientação das fibras durante a bobinagem.

\section{Olhando para o Futuro}

Sabendo-se que, os compósitos avançados são obtidos pela combinação de materiais com diferentes características físico-químicas e mecânicas e pela utilização de diferentes processos de manufatura, necessitando esses desempenhar funções estruturais cada vez mais 
exigentes, os trabalhos de pesquisa e desenvolvimento nesta área são cada vez mais importantes. A crescente utilização dos compósitos estruturais tem estimulado a formação de recursos humanos cada vez mais capacitados, de modo a atingir com êxito os desafios da obtenção de componentes com funções múltiplas, atendendo requisitos de utilização como: menor peso, maior desempenho mecânico, transparência à radiação, resistência à erosão, entre outras.

\section{Agradecimentos}

Ao Sr. Jeffferson Rodrigues Tavares pela preparação das figuras, ao Sr. Edmundo C. Ortiz da Hexcel Composites e à Divisão de Química do IAE por fornecer a figura do foguete VLS.

\section{Bibliografia sugerida}

1. Composites Technology . Yellow Pages 2000. International Edition, v. 6 (3), 6-20, 2000.
2. Sampe Journal, v. 35(6), 1999.

3. Sampe Journal, v. 35(4), 1999.

4. Sampe Journal, v. 35(3), 1999.

5. Sampe Journal, v. 35(2), 1999.

6. Sampe Journal, v. 35(1), 1999.

7. Sampe Journal, v. 34(6), 1998.

8. Sampe Journal, v. 34(5), 1998.

9. Sampe Journal, v. 34(4), 1998.

10. LEE, S.M. International Encyclopedia of Composites, v. 1-6, VCH, New York, 1991.

Matéria elaborada por Mirabel C. Rezende, Centro Técnico Aeroespacial, Instituto de Aeronáutica e Espaço, Divisão de Materiais e Edson C. Botelho, Centro Técnico Aeroespacial, Instituto Tecnológico de Aeronáutica. 